\title{
Ghrelin and growth hormone secretagogues, physiological and pharmacological aspect
}

\author{
Fernando Cordido ${ }^{1,2,3}$, Maria Luisa Isidro ${ }^{1}$, Rosa Nemiña ${ }^{2}$ and Susana Sangiao- \\ Alvarellos ${ }^{2,3}$ \\ ${ }^{1}$ Department of Endocrinology, Hospital Juan Canalejo A Coruña, Spain \\ ${ }^{2}$ Department of Investigation Hospital Juan Canalejo A Coruña, Spain \\ ${ }^{3}$ Department of Medicine University of La Coruña, A Coruña, Spain
}

\begin{abstract}
:
The first "growth hormone secretagogues" (GHSs) were discovered by Bowers et al. in 1977. In 1996 the GHSs receptor (GHS-R 1a) was cloned. The endogenous ligand for this receptor, ghrelin, was not identified until 1999. Synthetic molecules termed GHSs are substances that stimulate growth hormone (GH) release, via a separate pathway distinct from $\mathrm{GH}$ releasing hormone $(\mathrm{GHRH}) /$ somatostatin. Ghrelin displays strong GH-releasing activity through the activation of the GHS-R 1a. Apart from stimulating GH secretion, ghrelin and many synthetic GHSs: 1) stimulate prolactin and ACTH secretion; 2) negatively influence the pituitary-gonadal axis; 3) stimulate appetite and positive energy balance; 4) modulate pancreatic endocrine function and affect glucose levels; 5) have cardiovascular actions. The control of ghrelin secretion is not well established at present, although nutrition is an important regulator. Investigators have exploited the ability of GHSs and ghrelin to release GH by mechanisms different from GHRH as a diagnostic tool, which is the present main clinical use of some GHSs. As an alternative to GH, GH deficient conditions could be treated with any substance which would release endogenous $\mathrm{GH}$, such as synthetic GHSs. It is likely that GHSs, acting as either agonists or antagonists on different pathophysiological processes, might have some other clinical impact and therapeutic potential. At least theoretically ghrelin receptor antagonists could be anti-obesity drugs, as blockers of the orexigenic signal from the gastrointestinal tract to the brain. Inverse agonists of the ghrelin receptor, by blocking the constitutive receptor activity, might lower the set-point for hunger between meals.
\end{abstract}

Keywords: Ghrelin; Growth hormone secretagogues 


\section{INTRODUCTION}

Ghrelin is a 28-amino-acid peptide predominantly produced by the stomach that shows a unique structure with an n-octanoyl ester at its third serine residue, which is essential for its potent stimulatory activity on somatotroph secretion [1] (Fig. 1). Ghrelin, identified as an endogenous ligand for the growth hormone secretagogue receptor, functions as a somatotrophic and orexigenic signal from the stomach [1, 2]. Synthetic molecules termed "growth hormone secretagogues" (GHSs) are substances that stimulate and amplify pulsatile pituitary growth hormone $(\mathrm{GH})$ release, via a separate pathway distinct from $\mathrm{GH}$ releasing hormone $(\mathrm{GHRH})$ /somatostatin. The GH-releasing activity of GHSs is marked, dose related and reproducible after intravenous, subcutaneous, intranasal and even oral administration. The effect of GHSs on GH release is synergistic with that of GHRH, while it is only partially refractory to inhibitory influences, which nearly abolish the effect of GHRH. The activity of GHSs is not fully specific for GH secretion, since they also have slight releasing activity on other pituitary hormones and mediate GH independent biological activities through specific receptor subtypes in other central and peripheral endocrine and nonendocrine tissues [3].

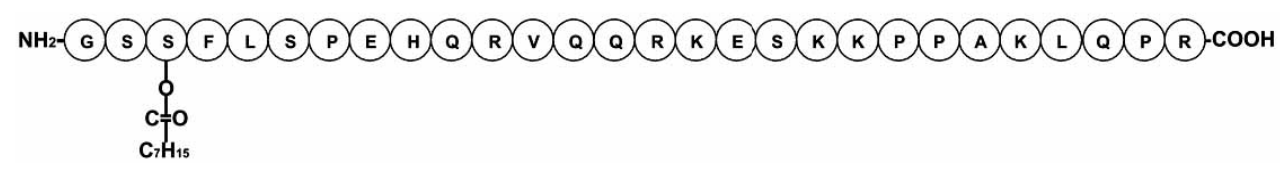

Fig (1). Primary sequence structure of human ghrelin.

The first GHSs were discovered by Bowers et al. in 1977 [4], when GHRH itself was not known yet. Experimenting with the enkephalin molecule he was able to identify, through systematic structural modification, a group of non-opioid peptides with GH releasing capabilities. Subsequently, through theoretical low-energy conformational calculations, computer modelling and structural modification, a series of small peptides able to stimulate GH secretion was produced [5]. In 1996 the G-protein-coupled seven transmembrane receptor (GHS-R 1a) through which these compounds acted was cloned [6]. The endogenous ligand for this receptor, ghrelin, was not identified until 1999 [1]. The discovery of ghrelin, therefore, started with the synthesis of its analogs and ended with the discovery of the natural ligand, via the discovery of the natural receptor. There are also other natural ligands of GHS-R 1a, apart from ghrelin [7], and GHS-R 1a is unlikely to be the only GHSs receptor. Ghrelin is most abundantly expressed in specialized cells in the oxyntic glands of the gastric epithelium, originally termed X/A-like cells [8]. Approximately 60-70\% of circulating ghrelin is secreted by the stomach, and most of the remainder originates in the small intestine [8]. It has been suggested that low-level ghrelin expression also occurs in several tissues outside the gut, including pancreatic islet cells, hypothalamus (arcuate nucleus and paraventricular nucleus), pituitary, lung, adrenal cortex, kidney, bone, testis and placenta [1, 7, 9].

There are different circulating molecular forms of ghrelin. The active form of ghrelin in terms of endocrine actions seems to need an n-octanoyl group at serine $3[7,10]$, since the unacylated form of ghrelin does not bind the GHS-R1a and is devoid of endocrine activity $[1,7,11]$. However, unacylated ghrelin is not biologically inactive $[7,11,12]$ (Table $\mathbf{1}$ ).

Table 1. Ghrelin General Characteristics. GPCR: G-Protein-Coupled Receptor [7, 11]

\begin{tabular}{cc}
\hline Structure & 28 Aminoacids Peptide \\
\hline Chromosomal gene locus & $3 \mathrm{p} 25-26$ \\
Synthesis & Gastric mucosa X/A like cells \\
Main stimulators & Preprandial, weight loss \\
Main inhibitors & Calories, obesity, somatostatin, insulin \\
Target organs & Hypothalamus, pituitary \\
Main actions & Growth, energy balance \\
Receptor & GHS-R (GPCR with 7 transmembrane domains) \\
\hline
\end{tabular}


On the basis of the bioinformatic prediction that another peptide also derived from the precursor proghrelin exists, a hormone named obestatin was isolated from the rat stomach. Treatment of rats with obestatin suppressed food intake, inhibited jejunal contraction, and decreased body-weight gain. Obestatin bound to the G-proteincoupled receptor GPR39. Thus, two peptide hormones with opposite actions in weight regulation are derived from the same ghrelin gene. [13]. Some of the initial results obtained with obestatin have not been confirmed by other groups [14-16], although it could participate in thirst regulation [17], and the physiological importance of obestatin is unclear at the present time. In human studies an increased circulating preprandial ghrelin to obestatin ratio has been found in obesity, suggesting that this ratio could be involved in the pathophysiology of obesity [18].

\section{GHRELIN SECRETION}

Ghrelin levels in blood increase during fasting and decrease during periods of feeding. Plasma ghrelin levels increase before meals and at night, and are rapidly suppressed by food intake, particularly by high calorie or high carbohydrate meals [19, 20].

The mechanisms responsible for postprandial suppression of ghrelin are unclear at present, and conflicting results have been obtained in different experimental situations. Diet composition influences postprandial ghrelin. Most studies have used mixed or carbohydrate rich test meals, which classically suppress ghrelin levels [21, 22]. After a solid carbohydrate-rich test meal and after an oral glucose load ghrelin levels clearly decreased, a fat-rich meal also decreased plasma ghrelin; protein intake, however, stimulated plasma ghrelin and there was no change in ghrelin after modified sham feeding or gastric distension [23]. Acylated ghrelin significantly fell after the ingestion of both a balanced and a high protein meal [24]. Greenman et al. found that ghrelin levels decreased significantly following a glucose load or a lipid meal, but protein did not affect ghrelin [25]. The calorie content of food is another factor regulating postprandial ghrelin. Increasing the calorie content of meals in normal-weight subjects progressively lowered nadir levels of ghrelin [26]. The depth of postprandial ghrelin suppression has been found proportional to the ingested caloric load [22]. Obese patients have lower fasting ghrelin levels, and the reduction after the consumption of different test meals was less than in the normal-weight subjects. The lowest postprandial levels in the obese were not different from the nadir in normal-weight volunteers after 1000-, 2000-, and 3000-kcal meals. Obese subjects demonstrate a much reduced ghrelin postprandial suppression [26]. Cephalic-vagal mechanisms could contribute to ghrelin regulation and modified sham feeding has been employed to test this hypothesis. Circulating ghrelin concentrations have been found to decrease by modified sham feeding as they are by real feeding in humans [27], although others did not find any significant change of ghrelin levels after modified sham feeding or gastric distension [23]. In other clinical model, chronic renal failure patients, ghrelin secretion has been found partially refractory to the acute inhibitory effect of oral feeding [28].

Different studies have found that insulin plays an important role in postprandial ghrelin regulation. Total and acylated ghrelin significantly fell after the ingestion of a mixed meal and acylated ghrelin levels correlated negatively with the postprandial insulin levels [28, 29]. After a carbohydrate-enriched breakfast the percentage of decrease in ghrelin between 0 and 30 min was inversely correlated with the percentage of increase in insulin and glucose [30]. It has also been found in adult men and women that meal-induced ghrelin suppression correlated with the postprandial rise in insulin [31]. In contrast with the previous studies, others could not find a clear relationship between postprandial ghrelin and insulin. During intravenous administration of glucose, representing fasting and postprandial conditions, a reduction in ghrelin was obtained only at supraphysiological insulin concentrations. This finding suggests that postprandial suppression of ghrelin is not directly regulated by glucose or insulin [32, 33]. In normal subjects we have found that postprandial plasma levels of both total and acylated intact ghrelin are suppressed after a mixed meal. Total ghrelin (expressed as percentage of baseline) and acylated ghrelin (expressed as percentage of baseline) after a mixed meal positively correlated with basal insulin resistance, suggesting that basal insulin resistance diminishes postprandial total and acylated ghrelin suppression. In contrast, the nadir of total ghrelin and the AUC of total ghrelin after the meal negatively correlated with the insulin peak and the AUC of insulin after a mixed meal, suggesting that postprandial insulin could be a major suppressor of total ghrelin after feeding [29]. These data suggest that insulin is a more likely candidate for ghrelin regulation, although it is possible that there are unidentified circulating factors that are associated with both high insulin and low ghrelin concentrations. 
Although obese patients with Prader-Willi syndrome, characterized by hyperphagia and obesity, have elevated ghrelin levels [34], the concentrations of fasting ghrelin are increased in anorexia and cachexia but reduced in idiopathic obesity [20, 21, 34, 35] and plasma ghrelin levels negatively correlated with body mass index, body fat mass and plasma leptin, insulin and glucose levels [36]. Insulin resistance has been postulated to play a role in determining this lower fasting plasma ghrelin in obese subjects [37].

Recent studies have raised the different biological actions of acylated and unacylated ghrelin. Barazonni et al. studied acylated and desacylated ghrelin levels in patients with metabolic syndrome. Plasma insulin and HOMA-IR were associated negatively with totalghrelin and desacylated-ghrelin but positively with acylated-ghrelin and acylated to desacylated ghrelin ratio. Compared with nonobese, obese metabolic syndrome patients had lower total-ghrelin and desacylated-ghrelin but comparable acylated-ghrelin and higher acylated/ desacylated-ghrelin ratio. They conclude that obesity could alter circulating ghrelin profile, and relative acylated-ghrelin excess could contribute to obesity-associated insulin resistance in metabolic syndrome [38].

All these data support an important role of ghrelin in the longterm regulation of energy homeostasis [21, 39]. Cholinergic stimulation leads to increased plasma ghrelin levels. Combined GHRHarginine administration similarly leads to increased plasma ghrelin levels [40]. In contrast, oral or intravenous glucose, insulin, glucagon and somatostatin suppress systemic ghelin levels [21, 41, 42].

Due to the well established GH-releasing activity of ghrelin [1, 6, 43, 44], it could be possible that GH regulates ghrelin secretion through a classical feedback system. In that sense it has been found that GH administration to GH-deficient patients induces a decrease in ghrelin levels [45]. Most, although not all, studies suggest that GH does not participate in the regulation of ghrelin secretion in humans [42, 46, 47]. Leptin could participate in the postprandial regulation of ghrelin. The percentage of changes in ghrelin concentrations after a carbohydrate rich meal between 30 and $180 \mathrm{~min}$ were correlated with the percentage of changes in leptin [30], although most of the studies did not suggest a significant role for leptin in ghrelin regulation [37].

Short-term infusions of peptide YY, oxyntomodulin, and urocortin, all putative appetite suppressing peptides, led to a decrease in plasma ghrelin levels [40]. Low systemic ghrelin has been reported in untreated hyperthyroidism, in male hypogonadism, in the polycystic ovary syndrome, in the presence of Helycobacter pylori-induced gastritis, or after total gastrectomy [40, 48]. The effect of exercise on ghrelin secretion has been studied in lean and obese adolescents. Total ghrelin was not affected by exercise; in contrast acylated ghrelin significantly increased after exercise, and this increase was greater in lean than in obese adolescents. Higher acylated ghrelin correlated with an increase in markers of appetite [49] (Table 2).

Table 2. Factors and Clinical Situations Associated with Changes in Circulating Ghrelin Levels [40]

\begin{tabular}{cc}
\hline Decreased Ghrelin & Increased Ghrelin \\
Obesity & Preprandial \\
Postprandial & Weight loss \\
Gastrectomy & Anorexia nervosa \\
Gastric bypass surgery & Cachexia \\
Helicobacter pylori-induced gastritis & Prader-Willi syndrome \\
Insulin & Cholinergic stimulation \\
\hline
\end{tabular}




\section{GHRELIN ACTIONS}

The biological activity of ghelin depends on an n-octanylation at position Ser3, at least in terms of GH release. Non-acylated ghrelin, which circulates in amounts far greater than the acylated form, does not displace radiolabeled ghrelin from its hypothalamic or pituitary binding sites and is unable to release $\mathrm{GH}$ in rats. Non-acylated ghrelin seems to be devoid of any endocrine action [50], although it exerts antiproliferative effects and is able to interact with specific receptors in cardiac muscle. Ghrelin displays strong GH-releasing activity [44] through the activation of the GH secretagogue receptor type 1a (GHS-R 1a). GHS-Rs are concentrated in the hypothalamus-pituitary unit but are also distributed in other central and peripheral tissues. Apart from stimulating GH secretion, ghrelin and many synthetic GHSs: 1) stimulate prolactin and ACTH secretion; 2) negatively influence the pituitary-gonadal axis; 3) stimulate appetite and positive energy balance; 4) modulate pancreatic endocrine function and affect glucose levels, 5) have cardiovascular actions [6] (Table 3).

Table 3. Ghrelin Actions [7, 11]

Stimulate GH secretion
Stimulate food intake
Stimulate weight gain
Stimulate prolactin and corticotrophin secretion
Stimulate gastrointestinal motility
Stimulate gastric acid secretion
Increase cardiac output
Decrease blood pressure
Modulate insulin-glucose homeostasis
Modulate inflammation
Modulate cell proliferation

\section{PITUITARY ENDOCRINE ACTIONS}

Ghrelin has a direct effect on pituitary somatotroph secretion in vitro and acts synergistically with GHRH to stimulate GH secretion $[1,51]$. Ghrelin may have direct hypothalamic effects to further induce GH secretion. In high doses, ghrelin may also stimulate prolactin, corticotrophin, and cortisol secretion [51]. Animal studies that involve genetic ablation suggest that neither ghrelin nor its classic GHS receptor is required for growth [52]. The relevance of these observations to human physiology is uncertain and is being challenged by the recent report of familial short stature in association with a GHS receptor mutation, leading to decrease binding to the mutant receptor [53]. The effect of ghrelin has been compared with that of hexarelin (HEX, a synthetic GHS) and GHRH. The GH response to ghrelin was clearly higher than that recorded after GHRH and even significantly higher than after hexarelin. Ghrelin administration also induced an increase in PRL, ACTH, and cortisol levels; these responses were higher than those elicited by HEX. The endocrine responses to ghrelin were not modified by the coadministration of HEX. On the other hand, the coadministration of ghrelin and GHRH had a real synergistical effect on GH secretion [7]. Ghrelin exerts a strong stimulatory effect on GH secretion in humans, releasing more GH than GHRH. The most important clinical application of GHSs at present is its use as a diagnostic tool in suspected GH deficiency. GHSs, when administered together with GHRH, exert a synergistic action on GH secretion and this combined administration is the most potent GH releaser to date. Clinical studies have demonstrated that the GHS-GHRH administration may be considered an optimal test of GH reserve in humans, as the GH secretion so elicited is not altered by gender, adiposity, or age [43, 54]. The combined administration of GHRH plus GHS is able to discriminate between healthy subjects and patients with adult GH deficiency, suggesting a considerable utility in the clinical setting [54-56]. Ghrelin has been used in adult patients with isolated childhood-onset $\mathrm{GH}$ deficiency. In this condition, however, the somatotroph response is markedly reduced while the lactotroph and corticotroph responsiveness to ghrelin is fully preserved, indicating that this endocrine activity is fully independent of the mechanisms underlying the GH-releasing effect. These results do not support the hypothesis that ghrelin deficiency is a major cause of isolated GH deficiency but suggest that ghrelin might represent a reliable provocative test to evaluate the maximal secretory capacity provided that appropriate cut-off limits are assumed [57]. The combined GHS-GHRH administration may be 
employed as a diagnostic test in other clinical situations. The use of GH secretagogues plus GHRH is an easy, reliable and accurate way of assessing GH secretion in cranially irradiated patients. Impairment of the GH releasable pool in irradiated patients, with a maximal provocative test, reflects alterations in the hypothalamic-pituitary unit caused by radiotherapy [58]. Synthetic GHSs have been used to increase GH secretion for longer periods. Maccario et al. showed that two or three daily sc injections of hexarelin augmented $24 \mathrm{~h} \mathrm{GH}$ secretion. IGF-I levels were not modified by these 1-day hexarelin treatment schedules [59].

\section{REGULATION OF ENERGY BALANCE}

In experimental animals, central or systemic ghrelin administration stimulates food intake [2, 60]. In humans, ghrelin infusion that leads to an increase in plasma ghrelin to preprandial levels stimulates hunger and spontaneous food intake [61]. Ghrelin is the only peripheral orexigenic factor, clearly established in the human [62]. Postprandial suppression of serum ghrelin is less robust in obese individuals, possibly contributing to the pathogenesis of obesity $[19,20]$.

In addition to its putative role as a short-term signal that regulates meal initiation and satiety, ghrelin appears to have a role as a longterm signal of nutritional status [63]. Systemic ghrelin levels are negatively associated with body adiposity and increase with weight loss induced by low calorie diet, exercise, cachexia or malignancy $[19,21,36,39]$. Weight gain leads to decreased systemic ghrelin levels [36]. Long-term ghrelin administration leads to weight gain in experimental animals by stimulating food intake, decreasing energy expenditure and spontaneous activity, and promoting adipogenesis [2, 7, 60, 61]. Several human studies support the hypothesis that ghrelin is important in the long-term regulation of energy balance. Patients with Prader-Willi syndrome have very high systemic ghrelin levels, hyperphagia, and extreme obesity, suggesting a role of ghrelin in the pathogenesis of obesity in this disease [34]. Postprandial suppression of serum ghrelin is less robust in patients with Prader-Willi syndrome as compared to matched obese and healthy controls [64]. Systemic ghrelin levels decrease in morbidly obese patients after gastric bypass surgery, suggesting that ghrelin may be involved in the mechanisms that lead to weight loss [20]. This observation has been confirmed in most, but not all subsequent studies [40, 65]. In experimental animals, ghrelin is more potent in stimulating appetite when administered centrally rather than systemically [2, 60,61]. Ghrelin leads to c-fos activation in arcuate hypotathalamic neurons that express the GHS receptor and are known to have an important role in energy homeostasis [60]. The expression of appetite-stimulating peptides neuropeptide Y (NPY) and agouti-related protein (AgRP) is increased by ghrelin in the arcuate nucleus $[40,66]$.

\section{PANCREATIC ENDOCRINE ACTIONS}

Studies in animals report conflicting results regarding the influence of ghrelin on insulin secretion [67-69]. In fact, ghrelin was able to stimulate insulin secretion from isolated rat pancreatic islets [68] and in vivo $[69,70]$. On the other hand, insulin secretion from isolated rat pancreas was found to be blunted by exposure to ghrelin [67]. Again in agreement with the assumption that ghrelin negatively modulates pancreatic $\square$-cell secretion, at least transiently, it has been found that ghrelin induces a slight but significant increase in plasma glucose levels and a reduction in insulin secretion in normal subjects in some [71-74] but not all studies [75, 76]. Recent studies have shown in rats, that systemic ghrelin administration decreased plasma insulin concentrations [77]. In rat islets, ghrelin receptor antagonist increased and exogenous ghrelin suppressed glucose-induced insulin release. Glucose-induced insulin release from islets was greater in ghrelin-knockout than wild-type mice [77].

\section{CARDIOVASCULAR ACTIONS}

Human data suggest that there is an association between systemic ghrelin levels and cardiovascular indexes [78]. In addition, ghrelin infusion has acute hemodynamic effects in healthy human volunteers, increasing cardiac index and stroke volume and decreasing blood pressure [79]. The effects of GHSs on left ventricular function and myocyte contractility have been studied in a model of congestive heart failure in pigs. With GHS treatment, the ratio of left ventricular mass to body weight increased by $44 \%$ from untreated values. Steady-state myocyte velocity of shortening was increased with GHS treatment. 
The improved left ventricular pump function that occurred with GHS treatment in this model was most likely a result of favourable effects on left ventricular myocardial remodelling and contractile processes [80]. Ghrelin improves cardiac structure and function, and attenuates the development of cardiac cachexia in rats with heart failure $[11,81]$. The hemodynamic and hormonal effects of ghrelin were studied in healthy men. Ghrelin elicited a marked increase in circulating $\mathrm{GH}$ (15-fold). Injection of ghrelin significantly decreased mean arterial pressure. Ghrelin significantly increased cardiac index and stroke volume index. GHS-R mRNA was detectable in the rats' aorta, left ventricles, and left atria, suggesting that ghrelin may cause cardiovascular effects through $\mathrm{GH}$-independent mechanisms. These data suggest that human ghrelin elicited a potent, long-lasting GH release and had beneficial hemodynamic effects via reducing cardiac afterload and increasing cardiac output, without an increase in heart rate [79]. In patients with coronary artery disease undergoing by-pass surgery, the acute administration of hexarelin clearly improves cardiac performance, it increases left ventricular ejection fraction, cardiac index and cardiac output. The cardiotropic effect of hexarelin is not shared by GHRH or by rhGH, indicating that it is not mediated by the increase in circulating GH levels but more likely reflects activation of specific cardiovascular GH secretagogue receptors [82]. There are results that suggest that ghrelin might have some role in cardiovascular control during normal pregnancy and in pregnancy-induced hypertension [83]. These studies together with the presence of GHSR in the heart suggest that GHS could have some future role as cardiovascular drugs due to their important hemodynamic effects.

\section{RENAL ACTIONS}

In patients with chronic renal failure, total ghrelin are increased, while those of acylated ghrelin are not [28]. Plasma total ghrelin levels decreased modestly and plasma acylated ghrelin more markedly after a standardized oral feeding, in patients with chronic renal failure treated with peritoneal dialysis. However, these changes were significantly attenuated, when compared with those observed in healthy controls, indicating that ghrelin secretion is partially refractory to the acute inhibitory effect of oral intake, in these patients. A hypertonic glucose-based dialysate peritoneal dialysis exchange was able to reduce significantly plasma levels of total and acylated ghrelin [28]. These alterations could contribute to early satiety and malnutrition, in these patients.

In a surgical model of chronic kidney disease in rats, treatment with ghrelin and ghrelin receptor agonists resulted in increased food intake and an improvement in lean body mass accrual that was related in part to a decrease in muscle protein degradation. Additionally, there was a decrease in circulating inflammatory cytokines. The authors conclude that ghrelin treatment in uremia results in improved lean mass accrual in part due to suppressed muscle proteolysis and possibly related to antiinflammatory effects [84]. In other experimental model in young uraemic rats, ghrelin increases appetite but not $24-\mathrm{h}$ food intake, stimulates GH secretion and does not improve growth [85]. In summary, in chronic renal failure ghrelin secretion is altered and has a potential therapeutic use.

\section{OTHER ACTIONS}

Ghrelin modulates gastrointestinal motility and gastric acid secretion [40]. Ghrelin stimulates gastric motility [86], which makes it a candidate as a prokinetic drug to treat postoperative ileus. Some evidence suggests that ghrelin may have direct anti-inflammatory effects [40], directly influence osteoblast growth [9], and modulate proliferation of neoplastic cells [7].

\section{TYPES OF GHSS}

Growth hormone secretagogues can have a peptide (growth hormone- releasing peptides, GHRPs) or a non-peptide structure. The first synthesized GHS were nonnatural peptides. Since peptides have low oral availability, extensive research has been carried out to synthesize non-peptidyl analogs, with better oral bioavailability and longer half-lives [87] (Table 4, 5). 
Table 4. Some of the More Relevant Peptidyl, Non-Peptidyl GHSs and Ghrelin, and the Year they were Synthesized or Discovered [7]

\begin{tabular}{ccc}
\hline Year & Peptidyl GHSs (GHRPs) & Nonpeptidyl GHSs \\
\hline & (D-Trp2)-metenkephalin & \\
1977 & GHRP-6 & L-692,429 \\
1984 & GHRP-1 & \\
1991 & & L-692,585 \\
1992 & GHRP-2 & MK-0677 \\
1993 & Hexarelin & \\
1994 & EP-51389 & NN-703 \\
1995 & & CP-424,391 \\
1996 & & SM-130686 \\
1999 & & EP-01572 \\
2000 & & \\
2001 & & \\
\hline
\end{tabular}

Table 5. Comparative Structures of Selected Growth Hormone Releasing Peptides and Met-Enkephalin. DbetaNal: D-2Naphthylalanine. DmeTrp: D-Methyl-Tryptophan [87]

\begin{tabular}{lcccccc}
\hline Aminoacid & 1 & 2 & 3 & 4 & 5 & 6 \\
\hline \\
Met-enkephalin & Tyr & Gly & Gly & Phe & Met-NH & \\
GHRP-6 & His & DTrp & Ala & Trp & Dphe & Lys-NH $_{2}$ \\
GHRP-1 & Ala & His & DbetaNal & Ala & Trp & Dphe Lys-NH \\
Dala & DbetaNal & Ala & Trp & DPhe & Lys-NH & GHRP-2 \\
His & DMeTrp & Ala & Trp & DPhe & Lys-NH & Hexarelin \\
& & & & & & \\
\hline
\end{tabular}

\section{Peptidic Growth Hormone Secretagogues (GHRPs)}

Growth hormone-releasing peptides are a series of tetra (e.g. G- 7134), penta (e.g. G-7039), hexa (GHRP-2, GHRP-6, hexarelin), and heptapeptides (GHRP-1) that have been shown to effectively release $\mathrm{GH}$ in animals and humans.

Tripeptides with substantial GH-releasing potency have also been synthesized [88] suggesting that the primary structure of a basic amino group and two aromatic amino acids is sufficient for this purpose. Although potent stimulants of GH release when administered parenterally, the hexapeptide GHRPs have modest oral bioavailability. Modifications of the GHRP structure and the synthesis of partial peptides increase oral bioactivity of these drugs.

\section{GHRP-6}

GHRP-6 was the first hexapeptide that demonstrated to actively release GH in vivo. It is the most widely studied GHRP and is specific for GH release in a variety of species, including man. One of its properties is that it shows strong GH-releasing activity after oral administration, although it has low bioavailability and a short-lasting effect. As a diagnostic tool, which is the actual most important clinical utility of GHSs, the combined administration of GHRH plus GHRP-6, both at saturating doses, is currently the most powerful releaser of growth hormone, devoid of side effects and convenient for the patient. 


\section{GHRP-2}

GHRP-2 has been shown to be effective in stimulating GH secretion in adults and children via the oral, intranasal as well as the iv route [89]. It was well tolerated, able to stimulate GH secretion and enhanced growth velocity without side effects or toxicities in an eight months trial of prepubertal children with growth failure [90]. It has recently been shown that subcutaneous administration of GHRP-2 to lean, healthy males, like ghrelin, increases food intake [91].

\section{Hexarelin}

Directly derived from GHRP-6 by substitution of 2-methyltryptophan for tryptophan [92], this compound is more rapidly absorbed than GHRP-6 due to its more lipophilic character and/or it is more resistant to degradation. This compound is more potent, has more chemical stability and less toxicity than GHRP-6. It is effective after intravenous, subcutaneous or intranasal administration. Apart from its capability to stimulate GH secretion, hexarelin displays a strong heart-protective activity against myocardial stunning in senescent rats, which seems to be specific to hexarelin or related GHRPs. Hexarelin also stimulates lactotroph and corticotroph secretion, stimulates feeding in the rat and has antiproliferative effects in human CALU-1 lung carcinoma cells.

\section{Hexarelin Derivatives}

By truncating hexarelin, the tripeptide EP-51389 was identified [93]. This tripeptide is more potent than hexeralin in stimulating GH secretion and is orally active in man. EP-51389 was further modified at its C-terminal region to incorporate a gem-diamino tryptophan residue [94], which was formylated to give EP-01572. This peptidomimetic GHS shows a very potent and selective GH-releasing activity after subcutaneous and even oral administration of very low doses [95].

\section{Other Peptidic Growth Hormone Secretagogues}

Ipamorelin is a pentapeptide derived from GHRP-1 with deletions of residues 4 and 5 [96]. It was identified within a series of compounds lacking the central dipeptide Ala-Trp of GHRP-1. In in vitro and in vivo animal studies ipamorelin released GH with a potency and efficacy similar to GHRP-6, did not affect FSH, LH, PRL or TSH levels, and, unlike GHRP-6 and GHRP-2, did not increase levels of ACTH or cortisol. Tabimorelin is a pseudo-peptide GHS that is orally active. It results from truncating ipamorelin and simultaneously reducing the hydrogen-bonding potential by incorporating of backbone isosteres. Parallel combinatorial chemistry was used to optimize these compounds, synthesizing tabimorelin [97]. This compound showed potency and efficacy similar to that of GHRP-6 in animal cell assays. After a single oral dose it did not stimulate ACTH, LH, FSH, TSH, PRL or cortisol secretion, which seemed to make it a promising potential candidate for treatment of GH deficiency. Nevertheless in a recently published study, a majority of GH deficient adults did not respond to NN703 [98].

\section{Non-Peptidic Growth Hormone Secretagogues}

Synthesis of non-peptide compounds with three-dimensional configurations in common with GHRP-6 but of diverse chemical structure, with GH-releasing activity by parenteral or oral administration and with enhanced and prolonged biologic activity, led to the nonpeptidic GHSs [99].

Researchers at Merk \& Co Inc discovered compounds that mimiced the structure of GHRP-6, the benzolactams. The replacement of the carboxylic acid moiety and the resolution of the $\mathrm{C}(3)$-chiral centre in the compound 11 led to the (R)-enantiomer L-692,429. This compound, when administered intravenously, stimulated release of GH in several animal models and in healthy young males without inducing significant changes in other pituitary hormones. In an attempt to discover substances with good oral bioavailability and more power, many analogs of L-692,429 were synthesized. The identification of L-739,943, was obtained from zwitterionic L-692,429. L-739,943 is orally active for the release of growth hormone in beagle dogs at doses as low as $0.5 \mathrm{mg} / \mathrm{kg}$. L-739,943 represents a significant breakthrough in 
terms of both potency and oral bioavailability, as compared to the prototype benzolactam L-692,429 [100].

Ye et al. reported the design, synthesis and biological activities of quinazolinone-based compounds as a new class of non-peptidic human GH secretagogue receptor agonists [101]. Introduction of a phenyl group at the C-6 position of the quinazolinone core and extension of the amine side-chain improved the binding activity of lead compound 4 against the GH secretagogue receptor. In all quinazolinone- type analogues, activities on the human GH secretagogue receptor increased when a phenethyl group was positioned at the C-2 position. Quinazolinones, such as compound 21, provide a potent alternative to the privileged structure based dipeptide design exemplified by MK-0677.

In an intensive research to discover potent oral GHSs, Merck synthesized a series of substances based on a spiroindanylpiperidine structure. L-162,752 (compound 17) produced good GH secretion after oral administration to dogs. Modifications were introduced on L-162,752 to increase its potency while retaining its oral bioavailability. In compound 18 the D-tryptophan residue was replaced by an ObenzylD-serine residue and a methane-sulfonylamide was introduced in the spiroindoline part of the structure. This secretagogue had high potency and excellent oral activity. MK-0677 [102,103] is the mesylate salt of compound 18. It is stable to peptidase degradation and shows a long-acting activity, which makes these GHs different from the benzolactam-based growth hormone secretagogues, which had a short duration of action and short half-lives, and from GHRP-6 or examorelin. Clinical studies using MK-0677 have been performed in healthy, both young and elderly, individuals. Sustained elevations in plasma GH and IGF-1 have been achieved after once-a-day oral dose. Fasting blood glucose, insulin and PRL also increased. Several sleep parameters have been reported to improve with treatment with MK- 0677.

Some oxindole derivates are potential GHSs. Modification of an oxindole derivative led to an entirely new class of non-peptidic GHSs represented by SM-130686 [104], which are structurally different from GHRP-6, hexarelin, MK-677 and NN703. SM-130686 has potent activity and a good pharmacokinetic profile in rats and might be a partial agonist for GHS-R 1a [105]. Repetitive administration of SM-130686 to rats, similar to repetitive administration of $\mathrm{GH}$, significantly increased the fat free mass by an amount almost equal to the gain in body weight.

\section{PHARMACOLOGICAL USES OF GHRELIN AND GHSS}

Investigators have exploited the ability of GHSs to release GH by mechanisms different from GHRH as a diagnostic tool [54-56], which is the present main clinical use of some GHSs. Since the commercialization of GH many studies have shown other potential medical uses of GH, apart from treatment of GH deficient children. Specifically, GH has been studied to treat physiological or pathological conditions characterized by a deficient GH secretion and conditions which are improved by the anabolic effects of GH. Nevertheless GH is expensive and has to be administered parenterally. As an alternative, these conditions could be treated with any substance which would release endogenous GH, such as synthetic GHSs. GHSs are being evaluated as potential therapeutic agents for enhancing circulating GH levels in patients with intact hypothalamic-pituitary axis, including children with growth hormone deficiency, as well as adults with catabolic states. Different studies have examined the intravenous and oral effects of GHSs. Recently the pharmacokinetics and hormonal effects of oral and intraduodenal EP01572, a synthetic ghrelin agonist, has been tested. The results revealed that oral and intraduodenal administration of EP01572 induced a rapid and dose-dependent increase in plasma drug concentrations and a potent GH release in healthy male volunteers [106]. Some new GHSs share some of the physiological actions of ghrelin without stimulating GH secretion. It is likely that GHSs, acting as either agonists or antagonists on different physiological and pathophysiological processes, might have some other clinical impact and therapeutic potential.

At present, ghrelin is the only peripheral orexigenic factor that is effective upon its intravenous administration [62]. At least theoretically ghrelin receptor antagonists could be anti-obesity drugs, as blockers of the orexigenic signal from the gastrointestinal tract to the brain. Inverse agonists of the ghrelin receptor, by blocking the constitutive receptor activity, might lower the set-point for hunger between meals [107]. Other mechanisms to decrease ghrelin activity could also be effective for the treatment of obesity [108]. In contrast, ghrelin and GHSs may be useful as orexigenic agents for the treatment of eating disorders such as anorexia nervosa [10]. Administration of ghrelin or GHSs can stimulate appetite and improve the nutritional status of these patients. However, plasma ghrelin concentrations in anorexia 
nervosa are high, indicating a situation of ghelin resistance. These drugs could also be useful in all the clinical situations associated with cachexia, such as malignancy, advanced cardiac failure, renal failure, postoperative patients and human immunodeficiency virus-lipodystrophy.

Ghrelin receptor antagonists could be useful for the treatment of diabetes. Ghrelin, through action on its receptor, GHS-R1a, exerts a variety of metabolic functions. Esler et al. examined the effects of novel small-molecule GHS-R1a antagonists on insulin secretion, glucose tolerance, and weight loss. Ghrelin dose-dependently suppressed insulin secretion from dispersed rat islets. This effect was fully blocked by a GHS-R1a antagonist. Consistent with this observation, a single oral dose of a GHS-R1a antagonist improved glucose homeostasis in an ip glucose tolerance test in rat. Improvement in glucose tolerance was attributed to increased insulin secretion. Daily oral administration of a GHS-R1a antagonist to dietinduced obese mice led to reduced food intake and weight loss due to selective loss of fat mass. Consistent with the hypothesis that ghrelin regulates feeding centrally, the anorexigenic effects of potent GHS-R1a antagonists in mice appeared to correspond with their brain exposure. These observations demonstrate that GHS-R1a antagonists have the potential to improve the diabetic condition by promoting glucosedependent insulin secretion and promoting weight loss [109].

Ghrelin stimulates gastric motility [86], which makes it a candidate as a prokinetic drug to treat postoperative ileus. Administration of ghrelin improves cardiac structure and function, and attenuates the development of cardiac cachexia in rats with heart failure [11,81]. These results suggest that ghrelin has cardiovascular protective effects through GH-dependent and-independent mechanisms. Thus ghrelin and GHSs may be new therapeutic agents for the treatment of severe chronic heart failure. Other claimed clinical uses of ghelin and GHSs include improvement of sleep quality and treatment of fractures, osteoporosis, aging, lupus erythematous, inflammatory bowel disease and central nervous system diseases, among others. Some of these indications have not been made for the nonpeptide GHSs, maybe because of their lower affinity for the GHS-R 1a or because the peptides bind to a yet unidentified receptor [7] (Table 6).

\begin{tabular}{cc} 
Table 6. Potential Therapeutic Uses of Ghrelin and GHSs Agonists and Antagonists [40] \\
\hline Ghrelin and GHSs Agonists & Ghrelin and GHSs Antagonists \\
\hline Diagnosis of GH deficiency & Obesity \\
Treatment of GH deficiency & Prader-Willi syndrome \\
Anorexia nervosa & \\
Cachexia of malignancy & \\
Other cachexias & \\
Chronic heart failure & \\
Gastrointestinal motility disorders & \\
Osteoporosis
\end{tabular}

In summary, ghrelin is the endogenous compound and GHSs are synthetic molecules that stimulate and amplify pulsatile pituitary growth hormone release and stimulate food intake. Ghrelin and GHSs is a field of continuous extensive research, to synthesize GHSs with better oral bioavailability and longer halflives. The potential applications of Ghrelin and GHSs are numerous and probably many more will be claimed in the future. GHSs are being evaluated as potential therapeutic agents for enhancing circulating $\mathrm{GH}$ levels in patients with intact hypothalamic-pituitary axis, including children with growth hormone deficiency, as well as adults with catabolic states.

\section{ACKNOWLEDGEMENTS}

This paper was partially supported by Grants FIS PI021479, PI051024, PI050983 and PI070413, Instituto de Salud Carlos III, Red de Grupos RGTO (G03/028) (Spain) and Xunta de Galicia PGIDT05PXIC91605PN, PS07/12 and Redes N² 2006/27. 


\section{REFERENCES}

[1] Kojima M., Hosoda H., Date Y., Nakazato M., Matsuo H., Kangawa K.: Ghrelin is a growth-hormone-releasing acylated peptide from stomach. Nature 402(6762), 656, (1999). [2] Tschop M., Smiley D.L., Heiman M.L.: Ghrelin induces adiposity in rodents. Nature 407(6806), 908, (2000).

[3] Ghigo E., Arvat E., Giordano R., Broglio F., Gianotti L., Maccario M., Bisi G., Graziani A. et al.: Biologic activities of growth hormone secretagogues in humans. Endocrine 14(1), 87, (2001).

[4] Bowers C.Y., Chang J., Momany F.A., Folkers K.: Effect of enkephalins and enkephalins analogs on release of pituitary hormones in vitro, Molecular Endocrinology, Ed.; Elservier: MacIntyre G, Szelke H, Amsterdam, pp. 287-292, (1977).

[5] Casanueva F.F., Dieguez C.: Growth Hormone Secretagogues: Physiological Role and Clinical Utility. Trends Endocrinol. Metab. 10(1), 30, (1999).

[6] Howard A.D., Feighner S.D., Cully D.F., Arena J.P., Liberator P.A., Rosenblum C.I., Hamelin M., Hreniuk D.L. et al:: A receptor in pituitary and hypothalamus that functions in growth hormone release. Science 273(5277), 974, (1996).

[7] van der Lely A., Tschöp M., Heiman M., Ghigo E.: Biological, physiological, pathophysiological, and pharmacological aspects of ghrelin. Endocr. Rev. 25(3), 426, (2004).

[8] Date Y., Kojima M., Hosoda H., Sawaguchi A., Mondal M.S., Suganuma T., Matsukura S., Kangawa K. et al.: Ghrelin, a novel growth hormonereleasing acylated peptide, is synthesized in a distinct endocrine cell type in the gastrointestinal tract of rats and humans. Endocrinology 141(11), 4255, (2000).

[9] Fukushima N., Hanada R., Teranishi H., Fukue Y., Tachibana T., Ishikawa H., Takeda S., Takeuchi Y. et al.: Ghrelin directly regulates bone formation. J. Bone Miner. Res. 20(5), 790, (2006).

[10] Muccioli G., Tschöp M., Papotti M., Deghenghi R., Heiman M., Ghigo E.: Neuroendocrine and peripheral activities of ghrelin: implications in metabolism and obesity. Eur. J. Pharmacol. 440(2-3), 235, (2002).

[11] Kojima M., Kangawa K.: Ghrelin: structure and function. Physiol. Rev. 85(2), 495, (2005).

[12] Gauna C., Meyler F.M., Janssen J.A., Delhanty P.J., Abribat T., van Koetsveld P., Hofland L.J., Broglio F. et al.: Administration of acylated ghrelin reduces insulin sensitivity, whereas the combination of acylated plus unacylated ghrelin strongly improves insulin sensitivity. J. Clin. Endocrinol. Metab. 89(10), 5035, (2004).

[13] Zhang J.V., Ren P.G., Avsian-Kretchmer O., Luo C.W., Rauch R., Klein C., Hsueh A.J.: Obestatin, a peptide encoded by the ghrelin gene, opposes ghrelin's effects on food intake. Science 310(5750), 996, (2005).

[14] Nogueiras R., Pfluger P., Tovar S., Arnold M., Mitchell S., Morris A., Perez-Tilve D., Vázquez M.J. et al.: Effects of obestatin on energy balance and growth hormone secretion in rodents. Endocrinology 148(1), 21, (2007).

[15] Holst B., Egerod K.L., Schild E., Vickers S.P., Cheetham S., Gerlach L.O., Storjohann L., Stidsen C.E. et al.: GPR39 signaling is stimulated by zinc ions but not by obestatin. Endocrinology 148(1), 13, (2007).

[16] Chartrel N., Alvear-Perez R., Leprince J., Iturrioz X., Reaux-Le Goazigo A., Audinot V., Chomarat P., Coge F. et al:: Comment on "Obestatin, a peptide encoded by the ghrelin gene, opposes ghrelin's effects on food intake". Science 315(5813), 766, (2007).

[17] Samson W.K., White M.M., Price C., Ferguson A.V.: Obestatin acts in brain to inhibit thirst. Am. J. Physiol. Regul. Integr. Comp. Physiol. 292(1), R637, (2007).

[18] Guo Z.F., Zheng X., Qin Y.W., Hu J.Q., Chen S.P., Zhang Z.: Circulating preprandial ghrelin to obestatin ratio is increased in human obesity. J. Clin. Endocrinol. Metab. 92(5),1875, (2007).

[19] Cummings D.E., Purnell J.Q., Frayo R.S., Schmidova K., Wisse B.E., Weigle D.S.: A preprandial rise in plasma ghrelin levels suggests a role in meal initiation in humans. Diabetes 50(8), 1714, (2001).

[20] Cummings D.E., Weigle D.S., Frayo R.S., Breen P.A., Ma M.K., Dellinger E.P., Purnell J.Q.: Plasma ghrelin levels after diet-induced weight loss or gastric bypass surgery. N. Engl. J. Med. 346(21), 1623, (2002).

[21] Shiiya T., Nakazato M., Mizuta M., Date Y., Mondal M.S., Tanaka M., Nozoe S., Hosoda H. et al.: Plasma ghrelin levels in lean and obese humans and the effect of glucose on ghrelin secretion. J. Clin. Endocrinol. Metab. 87(1), 240, (2002).

[22] Callahan H.S., Cummings D.E., Pepe M.S., Breen P.A., Matthys C.C., Weigle D.S.: Postprandial suppression of plasma ghrelin level is proportional to ingested caloric load but does not predict intermeal interval in humans. J. Clin. Endocrinol. Metab. 89(3), 1319, (2004).

[23] Erdmann J., Lippl F., Schusdziarra V.: Differential effect of protein and fat on plasma ghrelin levels in man. Regul. Pept. 116(1-3), 101, (2003).

[24] Al Awar R., Obeid O., Hwalla N., Azar S.: Postprandial acylated ghrelin status following fat and protein manipulation of meals in healthy young women. Clin. Sci. (Lond) 109(4), 405, (2005).

[25] Greenman Y, Golani N, Gilad S, Yaron M, Limon R, Stern N: Ghrelin secretion is modulated in a nutrient- and gender-specific manner. Clin. Endocrinol. 60(3), 382, (2004).

[26] le Roux C.W., Patterson M., Vincent R.P., Hunt C, Ghatei M.A., Bloom S.R.: Postprandial plasma ghrelin is suppressed proportional to meal calorie content in normal-weight but not obese subjects. J. Clin. Endocrinol. Metab. 90(2), 1068, (2005).

[27] Arosio M, Ronchi CL, Beck-Peccoz P, Gebbia C, Giavoli C, Cappiello V, Conte D, Peracchi M: Effects of modified sham feeding on ghrelin levels in healthy human subjects. J. Clin. Endocrinol. Metab. 89(10), 5101, (2004).

[28] Perez-Fontan M., Cordido F., Rodriguez-Carmona A., Garcia-Naveiro R., Isidro M.L., Villaverde P., GarciaBuela J.: Acute plasma ghrelin and leptin responses to oral feeding or intraperitoneal hypertonic glucose-based dialysate in patients with chronic renal failure. Kidney Int. 68(6), 2877, (2005). 
[29] Pérez-Fontán M., Cordido F., Rodríguez-Carmona A., Penín M., Díaz-Cambre H., López-Muñiz A., SangiaoAlvarellos S., García-Buela J: Shortterm regulation of peptide YY secretion by a mixed meal or peritoneal glucose- based dialysate in patients with chronic renal failure. Nephrol. Dial. Transplant. 23(11), 3696, (2008).

[30] Blom W.A., Stafleu A., de Graaf C., Kok F.J., Schaafsma G., Hendriks H.F.: Ghrelin response to carbohydrateenriched breakfast is related to insulin. Am. J. Clin. Nutr. 81(2), 367, (2005).

[31] Purnell J.Q., Weigle D.S., Breen P., Cummings D.E.: Ghrelin levels correlate with insulin levels, insulin resistance, and high-density lipoprotein cholesterol, but not with gender, menopausal status, or cortisol levels in humans. J. Clin. Endocrinol. Metab. 88(12), 5747, (2003).

[32] Schaller G., Schmidt A., Pleiner J., Woloszczuk W., Woltzt M., Luger A.: Plasma ghrelin concentrations are not regulated by glucose or insulin: a double-blind, placebo-controlled crossover clamp study. Diabetes 52(1), 16, (2003).

[33] Caixas A., Bashore C., Nash W., Pi-Sunyer X., Laferrere B. Insulin, unlike food intake, does not suppress ghrelin in human subjects. J. Clin. Endocrinol. Metab. 87(4), 1902, (2002).

[34] Haqq A.M., Farooqi I.S., O'Rahilly S., Stadler D.D., Rosenfeld R.G., Pratt K.L., LaFranchi S.H., Purnell J.Q.: Serum ghrelin levels are inversely correlated with body mass index, age, and insulin concentrations in normal children and are markedly increased in Prader-Willi syndrome. J Clin Endocrinol Metab 88(1), 174, (2003).

[35] Otto B., Cuntz U., Fruehauf E., Wawarta R., Folwaczny C., Riepl R.L., Heiman M.L., Lehnert P. et al.: Weight gain decreases elevated plasma ghrelin concentrations of patients with anorexia nervosa. Eur. J. Endocrinol. 145(5), 669, (2001).

[36] Ukkola O.: Ghrelin and insulin metabolism. Eur. J. Clin. Invest. 33(3), 183, (2003).

[37] McLaughlin T., Abbasi F., Lamendola C., Frayo R.S., Cummings D.: Plasma ghrelin concentrations are decreased in insulin-resistant obese adults relative to equally obese insulin-sensitive controls. J. Clin. Endocrinol. Metab. 89(4), 1630, (2004).

[38] Barazzoni R., Zanetti M., Ferreira C., Vinci P., Pirulli A., Mucci M., Dore F., Fonda M. et al.: Relationships between desacylated and acylated ghrelin and insulin sensitivity in the metabolic syndrome. J. Clin. Endocrinol. Metab. 92(10), 3935, (2007).

[39] Tschöp M., Weyer C., Tataranni P.A., Devanarayan V., Ravussin E., Heiman M.L.: Circulating ghrelin levels are decreased in human obesity. Diabetes 50(4), 707, (2001).

[40] Tritos N.A., Kokkotou E.G.: The physiology and potential clinical applications of ghrelin, a novel peptide hormone. Mayo Clin. Proc. 81(5), 653, (2006).

[41] Norrelund H., Hansen T.K., Orskov H., Hosoda H., Kojima M., Kangawa K., Weeke J., Moller N., Christiansen J.S., Jorgensen J.O.: Ghrelin immunoreactivity in human plasma is suppressed by somatostatin. Clin. Endocrinol. (Oxf) 57 (4), 539, (2002).

[42] Barkan A.L., Dimakari E.V., Jessup S.K., Symons K.V., Ermolenko M., Jaffe C.: Ghrelin Secretion in Humans Is Sexually Dimorphic, Suppressed by Somatostatin, and Not Affected by the Ambient Growth Hormone Levels. J. Clin. Endocrinol. Metab. 88(5), 2180, (2003).

[43] Cordido F., Peñalva A., Dieguez C., Casanueva F.F.: Massive growth hormone (GH) discharge in obese subjects after the combined administration of GH-releasing hormone and GHRP-6: evidence for a marked somatotroph secretory capability in obesity. J. Clin. Endocrinol. Metab. 76(4), 819, (1993).

[44] Alvarez P., Isidro L., Garcia-Buela J., Leal-Cerro A., Broglio F., Tassone F., Ghigo E., Dieguez C. et al.: Marked GH secretion after ghrelin alone or combined with GH-releasing hormone (GHRH) in obese patients. Clin. Endocrinol. 61(2), 250, (2004).

[45] Edén Engström B., Burman P., Holdstock C., Karlsson F.A.: Effects of growth hormone (GH) on ghrelin, leptin, and adiponectin in GH-deficient patients. J. Clin. Endocrinol. Metab. 88(11), 5193, (2003).

[46] Espelund U., Hansen T.K., Højlund K., Beck-Nielsen H., Clausen J.T., Hansen B.S., Orskov H., Jørgensen J.O. et al.: Fasting unmasks a strong inverse association between ghrelin and cortisol in serum: studies in obese and normal-weight subjects. J. Clin. Endocrinol. Metab. 90(2), 741, (2005).

[47] Freda P.U., Reyes C.M., Conwell I.M., Sundeen R.E., Wardlaw S.L.: Serum ghrelin levels in acromegaly: effects of surgical and long-acting octreotide therapy. J. Clin. Endocrinol. Metab. 88(5), 2037, (2003).

[48] Giménez-Palop O., Giménez-Pérez G., Mauricio D., Berlanga E., Potau N., Vilardell C., Arroyo J., GonzálezClemente J.M. et al.: Circulating ghrelin in thyroid dysfunction is related to insulin resistance and not to hunger, food intake or anthropometric changes. Eur. J. Endocrinol. 153(1), 73, (2005).

[49] Mackelvie K.J., Meneilly G.S., Elahi D., Wong A.C., Barr S.I., Chanoine J.P.: Regulation of appetite in lean and obese adolescents after exercise: role of acylated and desacyl ghrelin. J. Clin. Endocrinol. Metab. 92(2), 648, (2007).

[50] Broglio F., Benso A., Gottero C., Prodam F., Gauna C., Filtri L., Arvat E. van der Lely A.J. et al.: Non-acylated ghrelin does not possess the pituitaric and pancreatic endocrine activity of acylated ghrelin in humans. $\mathrm{J}$. Endocrinol. Invest. 26(3), 192, (2003).

[51] Arvat E., Macario M., Di Vito L., Broglio F., Benso A., Gotero C., Papotti M., Muccioli G. et al.: Endocrine activities of ghrelin, a natural growth hormone secretagogue (GHS), in humans: comparison and interaction with hexarelin, a nonnatural peptidyl GHS, and GH-releasing hormene. J. Clin. Endocrinol. Metab. 86(3), 1169, (2001).

[52] Sun Y., Ahmed S., Smith R.G.: Deletion of ghrelin impairs neither growth nor appetite. Mol. Cell Biol. 23(22), 7973, (2003).

[53] Pantel J., Legendre M., Cabrol S., Hilal L., Hajaji Y., Morisset S., Nivot S., Vie-Luton M.P. et al.: Loss of constitutive activity of the growth hormone secretagogue receptor in famlial short stature. J. Clin. Invest. 116(3), 760, (2006). 
[54] Popovic V., Leal A., Micic D., Koppeschaar H.P., Torres E., Páramo C., Obradovic C., Dieguez C. et al.: GHreleasing hormone and GH-releasing peptide-6 for diagnostic testing in GH-deficient adults. Lancet 356(9236), 1137, (2000).

[55] Baldelli R., Otero X.L., Camina J.P., Gualillo O., Popovic V., Dieguez C., Casanueva, F.F.: Growth hormone secretagogues as diagnostic tools in disease states. Endocrine 14(1), 95, (2001).

[56] Cordido F., Alvarez-Castro P., Isidro L., Casanueva F., Dieguez C.: Comparison between insulin tolerance test, growth hormone (GH)-releasing hormone (GHRH), GHRH plus acipimox and GHRH plus GH-releasing peptide6 for the diagnosis of adult GH deficiency in normal subjects, obese and hypopituitary patients. Eur. J. Endocrinol. 149(2), 117, (2003).

[57] Aimaretti G., Baffoni C., Broglio F., Janssen J.A., Corneli G., Deghenghi R., van der Lely A.J., Ghigo E. et al.: Endocrine responses to ghrelin in adult patients with isolated childhood-onset growth hormone deficiency. Clin. Endocrinol. 56(6), 765, (2002).

[58] Popovic V., Pekic S., Golubic I., Doknic M., Dieguez C., Casanueva F.F.: The impact of cranial irradiation on GH responsiveness To GHRH plus GHRP-6. J. Clin. Endocrinol. Metab. 87(5), 2095, (2002).

[59] Maccario M., Veldhuis J.D., Broglio F., Vito L.D., Arvat E., Deghenghi R., Ghigo E.: Impact of two or three daily subcutaneous injections of hexarelin, a synthtic growth hormone secretagogue, on $24 \mathrm{~h} G \mathrm{GH}$, prolactin, adrenocorticotropin and cortisol secretion in humans. Eur. J. Endocrinol. 146(2), 310, (2002).

[60] Nakazato M., Murakami N., Date Y., Kojima M., Matsuo H., Kangawa K., Matsukura S.: A role for Ghrelin in the central regulation of feeding. Nature 409(6817), 194, (2001).

[61] Wren A.M., Seal L.J., Cohen M.A., Brynes A.E., Frost G.S., Murphy K.G., Dhillo W.S., Ghatei M.A. et al.: Ghrelin enhances appetite and increases food intake in humans. J. Clin. Endocrinol. Metab. 86(12), 5992, (2001).

[62] Drazen D.L., Woods S.C.: Peripheral signals in the control of satiety and hunger. Curr. Opin. Clin. Nutr. Metab. Care 6(6), 621, (2003).

[63] Wortley K.E., del Rincon J.P., Murray J.D., Garcia K., Iida K., Thorner M.O., Sleeman M.W.: Absence of ghrelin protects against early-onset obesity. J. Clin. Invest. 115(12), 3573, (2005).

[64] Giménez-Palop O., Giménez-Pérez G., Mauricio D., González-Clemente J.M., Potau N., Berlanga E., Trallero R., Laferrère B. et al.: A lesser postprandial suppression of plasma ghrelin in Prader-Willi syndrome is associated with low fasting and a blunted postprandial PYY response. Clin. Endocrinol. (Oxf) 66(2), 198, (2007).

[65] Leonetti F., Silecchia G., Iacobellis G., Ribaudo M.C., Zappaterreno A., Tiberti C., Iannucci C.V., Perrotta N. et al.: Different plasma ghrelin levels after laparoscopic gastric bypass and adjustable gastric banding in morbid obese subjects. J. Clin. Endocrinol. Metab. 88(99), 4227, (2003).

[66] Cowley M.A., Smith R.G., Diano S., Tschop M., Pronchuk N., Grove K.L., Strasburger C.J., Bidlingmaier M. et al.: The distribution and mechanism of action of ghrelin in the CNS demonstrates a novel hypothalamic circuit regulating energy homeostasis. Neuron 37(4), 649, (2003).

[67] Egido E.M., Rodriguez-Gallardo J., Silvestre R.A., Marco J.: Inhibitory effect of ghrelin on insulin and pancreatic somatostatin secretion. Eur. J. Endocrinol. 146(2), 241, (2002).

[68] Date Y., Nakazato M., Hashiguchi S., Dezaki K., Mondal M.S., Hosoda H., Kojima M., Kangawa K. et al.: Ghrelin is present in pancreatic alpha-cells of humans and rats and stimulates insulin secretion. Diabetes 51(1), 124, (2002).

[69] Lee H.M., Wang G., Englander E.W., Kojima M., Greeley G.H.: Ghrelin, a new gastrointestinal endocrine peptide that stimulates insulin secretion: enteric distribution, ontogeny, influence of endocrine, and dietary manipulations. Endocrinology 143(1), 185, (2002).

[70] Adeghate E, Ponery AS.: Ghrelin stimulates insulin secretion from the pancreas of normal and diabetic rats. J. Neuroendocrinol. 2002; 14(7): 555-560.

[71] Broglio F., Arvat E., Benso A., Gottero C., Muccioli G., Papotti M., van der Lely A.J., Deghenghi R. et al.: Ghrelin, a natural GH secretagogue produced by the stomach, induces hyperglycemia and reduces insulin secretion in humans. J. Clin. Endocrinol. Metab. 86(10), 5083, (2001).

[72] Broglio F., Benso A., Castiglioni C., Gottero C., Prodam F., Destefanis S., Gauna C., van der Lely A.J. et al.: The endocrine response to ghrelin as a function of gender in human young and elderly subjects. J. Clin. Endocrinol. Metab. 88(4), 1537, (2003).

[73] Arosio M., Ronchi C.L., Gebbia C., Cappiello V., Beck-Peccoz P., Peracchi M.: Stimulatory effects of ghrelin on circulating somatostatin and pancreatic polypeptide levels. J. Clin. Endocrinol. Metab. 88(2), 701, (2003).

[74] Tassone F., Broglio F., Destefanis S., Rovere S., Benso A., Gottero C., Prodam F., Rossetto R. et al.: Neuroendocrine and metabolic effects of acute ghrelin administration in human obesity. J. Clin. Endocrinol. Metab. 88(11), 5478, (2003).

[75] Akamizu T., Takaya K., Irako T., Hosoda H., Teramukai S., Matsuyama A., Tada H., Miura K. et al.: Pharmacokinetics, safety, and endocrine and appetite effects of ghrelin administration in young healthy subjects. Eur. J. Endocrinol. 150(4), 447, (2004).

[76] Alvarez-Castro P., Isidro M.L., García-Buela J., Dieguez C., Casanueva F.F., Cordido F.: Effect of acute ghrelin administration on glycaemia and insulin levels in obese patients. Diabetes Obes. Metab. 8(5), 555, (2006).

[77] Dezaki K., Kakei M., Yada T.: Ghrelin uses Galphai2 and activates voltagedependent $K+$ channels to attenuate glucose-induced Ca2+ signaling and insulin release in islet beta-cells: novel signal transduction of ghrelin. Diabetes 56(9), 2319, (2007).

[78] Tritos N.A., Kissinger K.V., Manning W.J., Danias P.G.: Association between ghrelin and cardiovascular indexes in healthy obese and lean men. Clin. Endocrinol. 60(1), 60, (2004). 
[79] Nagaya N., Kojima M., Uematsu M., Yamagishi M., Hosoda H., Oya H., Hayashi Y., Kangawa K.: Hemodynamic and hormonal effects of human ghrelin in healthy volunteers. Am. J. Physiol. Regul. Integr. Comp. Physiol. 280(5), R1483, (2001).

[80] King M.K., Gay D.M., Pan L.C., McElmurray J.H., Hendrick J.W., Pirie C., Morrison A., Ding C. et al.: Treatment with growth hormone secretagogues in a model of developing heart failure: Effects on ventricular and myocyte function. Circulation 103(2), 308, (2001).

[81] Chang L., Ren Y., Liu X.G., Yang J., Geng B., Weintraub N.L., Tang C.: Protective effect of ghrelin on ischemia/reperfusion injury in the isolated rat heart. J. Cardiovasc. Pharmacol. 43(2), 165, (2004).

[82] Broglio F., Guarracino F., Benso A., Gottero C., Prodam F., Granata R., Avogadri E., Muccioli G. et al.: Effects of acute hexarelin administration on cardiac performance in patients with coronary artery disease during bypass surgery. Eur. J. Pharmacol. 448(7), 193, (2002).

[83] Makino Y., Hosoda H., Shibata K., Makino I., Kojima M., Kangawa K., Kawarabayashi T.: Alteration of plasma ghrelin levels associates with the blood pressure in pregnancy. Hypertension 39(3), 781, (2002).

[84] Deboer M.D., Zhu X., Levasseur P.R., Inui A., Hu Z., Han G., Mitch W.E., Taylor J.E. et al.: Ghrelin treatment of chronic kidney disease: improvements in lean body mass and cytokine profile. Endocrinology 149(2), 827, (2008).

[85] Alvarez-García O., García-López E., Rodríguez J., Gil-Peña H., Molinos I., Carbajo-Pérez E., Santos F.: Administration of ghrelin to young uraemic rats increases food intake transiently, stimulates growth hormone secretion and does not improve longitudinal growth. Nephrol. Dial. Transplant. 22(5), 1309, (2007).

[86] Dornonville De la Cour C., Lindström E., Norlén P., Håkanson R.: Ghrelin stimulates gastric emptying but is without effect on acid secretion and gastric endocrine cells. Regul. Pept. 120(1-3), 23, (2004).

[87] Isidro M.L., Cordido F.: Growth hormone secretagogues. Comb. Chem. High T. Scr. 9(3), 175, (2006).

[88] Yang L., Morriello G., Pan Y., Nargund R.P., Barakat K., Prendergast K., Cheng K., Chan W.W. et al.: Tripeptide growth hormone secretagogues. Bioorg. Med. Chem. Lett. 8(7), 759, (1998).

[89] Pihoker C., Middleton R., Reynolds G.A., Bowers C.Y., Badger T.M.: Diagnostic studies with intravenous and intranasal growth hormone-releasing peptide-2 in children of short stature. J. Clin. Endocrinol. Metab. 80(10), 2987, (1995).

[90] Mericq V., Cassorla F., Salazar T., Avila A., Iniguez G., Bowers C.Y., Merriam G.R.: Effects of eight months treatment with graded doses of a growth hormone $(G H)$-releasing peptide in GH-deficient children. J. Clin. Endocrinol. Metab. 83(7), 2355, (1998).

[91] Laferrère B., Abraham C., Rusell C.D., Bowers C.Y.: Growth hormone releasing peptide-2 (GHRP-2), like ghrelin, increases food intake in healthy men. J. Clin. Endocrinol. Metab. 90(2), 611, (2005).

[92] Deghenghi R., Cananzi M.M., Torsello A., Battisti C., Muller E.E., Locatelli V.: GH-releasing activity of Hexarelin, a new growth hormone releasing peptide, in infant and adult rats. Life Sci. 54(18), 1321, (1994).

[93] Deghenghi R.: In Impervious peptides as GH secretagogues. Ghigo E., Boghem M., Casanueva F.F., Dieguez C., Eds. Elsevier Science B.V.: Amsterdam, pp. 19-24, (1999).

[94] Guerlavais V., Boeglin D., Mousseaux D., Oiry C., Heitz A., Deghenghi R., Locatelli V., Torsello A. et al.: New active series of growth hormone secretagogues. J. Med. Chem. 46(7), 1191, (2003).

[95] Broglio F., Boutignon F., Benso A., Gottero C., Prodam F., Arvat E., Ghe C., Catapano F. et al.: EP1572: a novel peptido-mimetic GH secretagogue with potent and selective GH-releasing activity in man. J. Endocrinol. Invest. 25(8), RC26, (2002).

[96] Raun K., Hansen B.S., Johansen N.L., Thogersen H., Madsen K., Ankersen M., Andersen P.H.: Ipamorelin, the first selective growth hormone secretagogue. Eur. J. Endocrinol. 139(5), 552, (1998).

[97] Hansen B.S., Raun K., Nielsen K.K., Johansen P.B., Hansen T.K., Peschke B., Lau J., Andersen P.H. et al.: Pharmacological characterisation of a new oral GH secretagogue. Eur. J. Endocrinol. 141(2), 180, (1999).

[98] Svensson J., Monson J.P., Vetter T., Hansen T.K., Savine R., Kann P., Bex M., Reincke M. et al.: Oral administration of the growth hormone secretagogue NN703 in adult patients with growth hormone deficiency. Clin. Endocrinol. (Oxf) 58(5), 572, (2003).

[99] Fehrentz J.A., Martinez J., Boeglin D., Guerlavais V., Deghenghi R.: Growth hormone secretagogues: past, present and future. IDrugs, 5(8), 804, (2002).

[100] DeVita R.J., Bochis R., Frontier A.J., Kotliar A., Fisher M.H., Schoen W.R., Wyvratt M.J., Cheng K. et al.: A potent, orally bioavailable benzazepinone growth hormone secretagogue. J. Med. Chem. 41(10), 1716. (1998).

[101] Ye Z., Gao Y., Bakshi R.K., Chen M.H., Rohrer S.P., Feighner S.D., Pong S.S., Howard A.D. et al.: Modeling directed design and biological evaluation of quinazolinones as non-peptidic growth hormone secretagogues. Bioorg. Med. Chem. Lett. 10(1), 5, (2000).

[102] Smith R.G., Cheng K., Schoen W.R., Pong S.S., Hickey G., Jacks T., Butler B., Chan W.W. et al.: A nonpeptidyl growth hormone secretagogue. Science 260(5114), 1640, (1993).

[103] Patchett A.A., Nargund R.P., Tata J.R., Chen M.H., Barakat K.J., Johnston D.B., Cheng K., Chan W.W. et al.: Design and biological activities of L-163,191 (MK-0677): a potent, orally active growth hormone secretagogue. Proc. Natl. Acad. Sci. USA 92(15), 7001, (1995)

[104] Tokunaga T., Hume W.E., Umezome T., Okazaki K., Ueki Y., Kumagai K., Hourai S., Nagamine J. et al.: Oxindole derivatives as orally active potent growth hormone secretagogues. J. Med. Chem. 44(26), 4641, (2001).

[105] Nagamine J., Nagata R., Seki H., Nomura-Akimaru N., Ueki Y., Kumagai K., Taiji M., Noguchi H.: Pharmacological profile of a new orally active growth hormone secretagogue, SM-130686. J. Endocrinol. 171(3), 481, (2001). 
[106] Piccoli F., Degen L., MacLean C., Peter S., Baselgia L., Larsen F., Beglinger C., Drewe J.: Pharmacokinetics and pharmacodynamic effects of an oral ghrelin agonist in healthy subjects. J. Clin. Endocrinol. Metab. 92(5), 1814, (2007).

[107] Holst B., Schwartz T.W.: Ghrelin receptor mutations-too little height and too much hunger. J. Clin. Invest. 116(3), 637, (2006).

[108] Zorrilla E.P., Iwasaki S., Moss J.A., Chang J., Otsuji J., Inoue K., Meijler M.M., Janda K.D.: Vaccination against weight gain. Proc. Natl. Acad. Sci. USA 103(35), 13226, (2006).

[109] Esler W.P., Rudolph J., Claus T.H., Tang W., Barucci N., Brown S.E., Bullock W., Daly M. et al.: Smallmolecule ghrelin receptor antagonists improve glucose tolerance, suppress appetite, and promote weight loss. Endocrinology 148(11), 5175, (2007). 